\title{
In vitro amplification of hepatitis B virus sequences from liver tumour DNA and from paraffin wax embedded tissues using the polymerase chain reaction
}

\author{
Y-MD LO, W Z MEHAL, K A FLEMING \\ From the University of Oxford, Nuffield Department of Pathology, John Radcliffe Hospital, Oxford
}

SUMMARY A 185 base pair fragment from the core-polymerase overlap region of the hepatitis B virus (HBV) genome was amplified using the polymerase chain reaction (PCR). The results were compared with those of Southern blotting on extracted DNA from eight hepatocellular carcinomata. The data agreed with those of Southern blotting in six cases (two positive, four negative) but in two other positive cases PCR failed to amplify HBV sequences. This suggests deletion or mutation, or both, of this viral region in these cases. PCR was also used to amplify HBV sequences from formalin fixed, paraffin wax embedded tissue. Tissue inhibition of PCR occurred which increased with the number of tissue sections. It was present in tissues from different organs and species and fixed by different procedures, thus highlighting the need for a positive control during amplification. Use of formalin fixed Alexander cells, however, showed a sensitivity of one viral copy per 5000 cells. Confirmation of the identity of the PCR products was carried out using PCR-generated biotinylated probes, and suggested the insertion of extra nucleotide sequences or infection with an HBV variant in one case.

Hepatitis B virus (HBV) infection is a major public health problem, with a carrier population of over 200 million throughout the world. ${ }^{1}$ If $\mathrm{HBV}$ infection is chronic, there may be serious sequelae such as chronic hepatitis, cirrhosis, and hepatocellular carcinoma. Although an immune mediated pathogenic mechanism has been suggested ${ }^{23}$ the detailed molecular basis for liver damage associated with HBV and hepatocarcinogenesis has not been worked out. It is not clear whether HBV causes liver cancer by promoter-insertion adjacent to a cellular oncogene, or by the activation of some viral gene products, or by causing chronic inflammation, or by some yet unknown mechanisms. ${ }^{4}$ It is also not clear whether viral heterogeneity might be related to pathogenesis.

The advent of molecular biology permits the examination, on a molecular level, of the state of HBV-DNA in various liver diseases. This has led to observations which are inconsistent with conventional serology such as the detection of HBV-DNA in a significant proportion of patients with hepatitis $B$ surface antigen (HBsAg) negative chronic liver disease. ${ }^{56}$ Controversies started to arise, however, when other investigators, using recombinant DNA techniques, failed to confirm these observations. ${ }^{7-9}$

Accepted for publication 31 March 1989
While one cause of this discrepancy might be a geographical difference in HBV virology (such as the endemic rate), it is equally possible that it is the result of methodological differences among laboratories. For example, it is well known that sensitivity of the Southern blot varies from laboratory to laboratory.

To circumvent the problems associated with the lack of sensitivity of conventional methods and to allow us to examine samples from different geographical regions, we decided to tackle the problem using the polymerase chain reaction (PCR). ${ }^{1011}$ PCR is a recently described method for amplifying specific DNA sequences in vitro, using repeated cycles of thermal denaturation, primer annealing, and extension using a DNA polymerase. This procedure results in an exponential increase in the number of target DNA molecules and offers unprecedented sensitivity over conventional methods. PCR also has the added advantage that high molecular weight DNA is not required for successful amplification. Thus PCR has been applied to DNA extracted from paraffin wax embedded tissues ${ }^{1213}$ and to tissue sections without prior DNA extraction..$^{14}$ is The ability to use paraffin wax embedded material allows archival material to be used and enables large scale international studies to be carried out as material can easily be transferred from country to country. 
The combined advantages of exquisite sensitivity and the ability to use routinely processed materials prompted us to adopt PCR for the detection of HBV. The result is the development of a highly sensitive and completely non-isotopic detection system for HBV, with potential for research and diagnostic applications.

\section{Material and methods}

DNA from eight hepatocellular carcinomata was donated by Dr MF Bassendine. Agarose gel electrophoresis on unrestricted tumour DNA showed that the samples were of high molecular weight.

From each tumour sample $18 \mu \mathrm{g}$ was digested with Hind III (New England BioLabs) overnight according to the manufacturer's recommendations. Half a microgram of each restricted sample was run on a mini-gel to ensure complete digestion. The remaining samples were run on an $0.8 \%$ gel and Southern transfer and hybridisation were done essentially as described. ${ }^{16}$ The probe was a biotinylated plasmid containing a full length $\mathrm{HBV}$ insert (pHBV130). ${ }^{17}$ Biotinylation was performed by nick-translation. ${ }^{16}$

The Alexander cell line (PLC/PRF/5), ${ }^{18}$ containing integrated HBV sequences, was obtained from the Sir William Dunn School of Pathology, Oxford. CaSki cells, ${ }^{19}$ which contain integrated human papilloma virus, were obtained from the American Tissue Culture Collection. They were grown in Dulbecco MEM and RPMI1640, respectively, trypsinised, and cell suspensions fixed in neutral buffered formalin for 24 hours. Cells were washed in phosphate buffered saline, spun, and serial dilutions done. The cells were then subject to 50 cycles of PCR.

Paraffin wax blocks were retrieved from the archives of the Nuffield Department of Pathology, University of Oxford, Oxford. The tissues had been fixed in $10 \%$ buffered formol-saline and processed routinely by sequential washes in methylated spirits and xylene and embedded in paraffin wax.

\section{PREPARATION OF PARAFFIN WAX SECTIONS FOR PCR}

One to ten $5 \mu \mathrm{m}$ sections were cut from paraffin wax blocks and placed in a $1.5 \mathrm{ml}$ Eppendorf tube. Subsequent processing was as previously described. ${ }^{14}$ In brief, the sections were deparaffinised in $400 \mu \mathrm{l}$ xylene (Aldrich, HPLC grade), vortexed for one minute, and spun for five minutes (Microcentaur). The xylene was pipetted off and its residue was removed with $400 \mu \mathrm{l}$ of $95 \%$ ethanol. This was followed by vortexing (one minute) and spinning (five minutes). Most of the ethanol was pipetted off and the rest was removed by vacuum desiccation for 15 minutes. One hundred $\mu \mathrm{l}$ of PCR mix was added to the tubes, heated at $94^{\circ} \mathrm{C}$ for $10-15$ minutes, followed by 50 cycles of PCR.

POLYMERASE CHAIN REACTION (PCR)

PCR was carried out essentially as described." Five units of Thermus aquaticus (Taq) DNA polymerase (Perkin-Elmer Cetus) were used for each reaction. The reaction buffer and deoxynucleotide triphosphates were obtained from Perkin-Elmer Cetus GeneAmp DNA Amplification Reagent Kit.

Each cycle of PCR consisted of thermal denaturation at $94^{\circ} \mathrm{C}$ (two minutes), primer annealing at $55^{\circ} \mathrm{C}$ (two minutes), and extension at $72^{\circ} \mathrm{C}$ (three minutes), carried out manually using heat blocks (Techne DriBlock DB-1). During the last cycle, extension time was increased by an additional seven minutes. Thirty cycles of PCR were carried out for extracted genomic DNA and 50 were performed for formalin fixed cell lines and paraffin wax embedded tissues.

\section{Oligonucleotide PCR primers}

Oligonucleotides were synthesised by British Biotechnology Limited. All sequences are written from $5^{\prime}$ to $3^{\prime}$.

PCR1: GATTGAGATCTTCTGCGACGC

PCR2: GAGTGTGGATTCGCACTCCTC

HBVINT5: AGACCACCAAATGCCCCTATC

HBVINT3: CGTCTGCGAGGCGAGGGA

$\beta$-Globin A: ATGGTGCACCTGACTCCTGAGG

$\beta$-Globin B: GCCATCACTAAAGGCACCGAGC

PCR1, PCR2, HBVINT5 and HBVINT3 sequences were obtained from published data. ${ }^{20}$ Beta-globin A and $\beta$-globin $B$ were designed from sequence data. ${ }^{21}$

\section{Biotinylated probe for $P C R$ products}

A biotinylated probe for detection of HBV-PCR products was produced as described ${ }^{22}$ using HBVINT5 and HBVINT3 as primers and plasmid pHBV130 (which contains a full length HBV insert) ${ }^{17}$ as target. Southern transfer of PCR products and detection of biotinylated probe were performed essentially as described. ${ }^{16}$

\section{Results}

AMPLIFICATION OF HBV SEQUENCES FROM

HEPATOCELLULAR CARCINOMATA

As an initial step to optimise a PCR-based detection system for HBV, we used as our targets DNA from hepatocellular carcinomata. This is because it has been well established that integration of HBV-DNA occurs in a proportion of hepatocellular carcinomata. ${ }^{23-25}$ Our PCR target was a 185 base pair fragment, flanked by primers PCR1 and PCR2, in the region where the core antigen gene overlaps the polymerase gene ${ }^{26}$ and was chosen because of its conservation among different subtypes of $\mathrm{HBV}{ }^{20}$ 
We performed simultaneous Southern blot and PCR analyses on a series of eight hepatocellular carcinomata. The results are summarised in table 1 and typical data are shown in fig 1 .

In most cases $(1,4,5-8)$ the results of Southern blotting agree with those generated by PCR. Numbers 2 and 3, however, are exceptions (table 1, fig 1); the importance of this discrepancy will be discussed later.

After having optimised the HBV-PCR on extracted DNA, we next proceeded to adapt the method for formalin fixed, paraffin wax embedded material.

\section{SENSITIVITY OF HBV-PCR ON FORMALIN FIXED MATERIAL}

To investigate the sensitivity of PCR on formalin fixed material, we used a model system involving serial dilutions of Alexander cells ${ }^{18}$ in CaSki cells, ${ }^{19}$ while keeping the total number of cells constant $\left(1 \times 10^{5}\right.$ cells). This number was chosen because it approxi-

Table 1 Comparison between Southern blot and PCR on a series of eight hepatocellular carcinomata

\begin{tabular}{lll}
\hline $\begin{array}{l}\text { Hepatocellular } \\
\text { carcinomata }\end{array}$ & Southern blot & PCR \\
\hline 1 & + & + \\
2 & + & - \\
3 & + & - \\
4 & + & + \\
5 & - & - \\
6 & - & - \\
7 & - & - \\
8 & - & \\
\hline
\end{tabular}

mated to the number of hepatocytes (average cellular volume $\left.11000 \mu \mathrm{m}^{3}\right)^{27}$ in $10 \times 5 \mu \mathrm{m}$ sections of a typical liver biopsy specimen measuring $2 \mathrm{~cm} \times 0.1 \mathrm{~cm}$. Alexander cells contain at least seven copies of integrated HBV-DNA which have been cloned and partially sequenced. ${ }^{28}$ Two of these contain the 185 base pair region flanked by PCR1 and PCR2.

The relative ratios and the actual number of each type of cells in the various dilutions are shown in table 2.

Fig 2 shows the results of PCR on the cell mixtures in table 2. PCR had a sensitivity down to one viral copy per 5000 cells, using visualisation by ethidium bromide staining as the detection method. Detection using Southern blotting (see below) can be expected to increase the sensitivity by one to two orders of magnitude.

\section{THE DEMONSTRATION OF PCR INHIBITOR(S) IN PARAFFIN WAX EMBEDDED SECTIONS}

An inhibitor of Taq polymerase in human genomic DNA has recently been described. ${ }^{29}$ To determine whether an inhibitor exists in paraffin wax embedded sections we added a fixed quantity $(1 \mathrm{ng}$ ) of plasmid pHBV130, ${ }^{17}$ containing a full length $\mathrm{HBV}$ insert, to a varying number of sections of a liver wedge section (surface area $0.5 \mathrm{~cm}^{2}$ ) from a patient negative for hepatitis B surface antigen (HBsAg).

Fig 3 shows the results after 25 cycles of amplification. As can be seen, the amount of PCR product varied inversely with the number of tissue sections, thus confirming the existence of PCR inhibitor(s) in the paraffin wax sections.

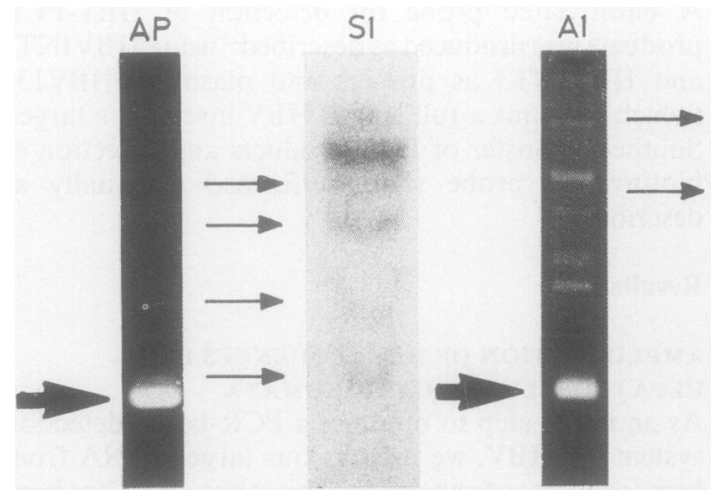

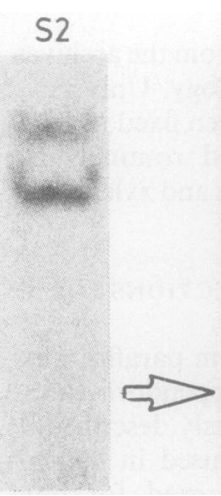

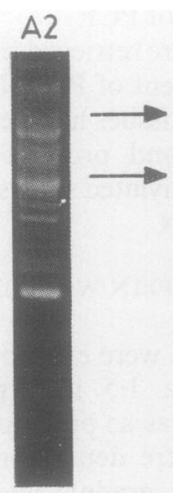

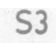

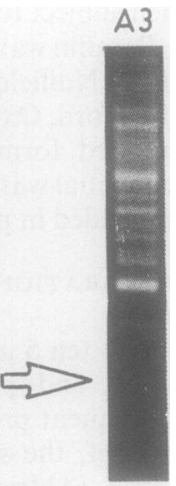

Fig 1 Southern blot and amplification results of hepatocellular carcinomata 1, 2, and 3. AP: amplification of plasmid pHBV13017 showing expected amplification product of 185 base pair ( $\triangle$ ). S1, S2, S3: Southern blots of DNA from hepatocellular carcinomata 1, 2, 3, showing integration of $\mathrm{HBV}$ in all three tumours (arrows). A1, A2, A3: Amplified product of hepatocellular carcinomata 1, 2, 3. A1 shows a strong signal at 185 base pairs ( $\triangle$ ), but A2 and $A 3$ have no amplification product of the expected size $(\Delta)$. Higher molecular weight non-specific bands are present in every genomic amplification and do not hybridise to an $\mathrm{HBV}$ specific probe (results not shown). All samples were amplified simultaneously, with a negative and positive control, and run on the same $2 \%$ agarose gel, with pBR322 digested by Msp I as a marker. 
Table 2 Dilutions of Alexander (A) cells with CaSki (C) cells to determine the sensitivity of $P C R$

\begin{tabular}{llll}
\hline Lane & Cell number & $A: C$ & $H: G$ \\
\hline C & $0: 100,000$ & $O$ & $O$ \\
1 & $33,400: 66,600$ & $1: 2$ & $1: 1$ \\
2 & $4,762: 95,238$ & $1: 20$ & $1: 10$ \\
3 & $498: 99,502$ & $1: 200$ & $1: 100$ \\
4 & $50: 99,950$ & $1: 2,000$ & $1: 1,000$ \\
5 & $10: 99,990$ & $1: 10,000$ & $1: 5,000$ \\
6 & $5: 99,995$ & $1: 20,000$ & $1: 10,000$ \\
B & $0: 0$ & & \\
\hline
\end{tabular}

H:G = Number of HBV-PCR targets: number of cells (fig 2).

We also attempted to remove inhibition by heating sections from the same liver to $94^{\circ} \mathrm{C}$ in water three times before adding the PCR mix and (in a separate experiment) performing PCR in four times the reaction volume $(400 \mu \mathrm{l})$. Inhibition was not affected by either treatment, suggesting that it could not be removed by simple heating or dilution. Other procedures that were tried included more extensive deparaffinisation (three times in xylene), washing in acetone after the $95 \%$ ethanol wash, digesting the tissue with proteinase $\mathrm{K}(50 \mu \mathrm{g} / \mathrm{ml}$ for 30 minutes) after deparaffinisation, adding $0.2 \%$ nuclease free bovine serum albumin to the PCR mix, and washing in PCR mix three times before adding the final PCR mix. All of these did not remove the inhibition.

To further elucidate the nature of inhibition, with regard to organ and species of origin and fixation procedures, we performed a similar experiment by amplifying pHBV130 in the presence of sections of rat kidney and mouse liver fixed in formalin or ethanol/ acetic acid. Fig 4 shows that inhibition occurred in all cases, although to varying extent, thus showing that it was not specific to human liver or to formalin fixation.

\section{AMPLIFICATION OF $\boldsymbol{\beta}$-GLOBIN AND HBV SEQUENCES FROM PARAFFIN WAX EMBEDDED SECTIONS}

We next applied PCR to routinely processed paraffin wax embedded sections using a protocol modified from that published by Shibata $e t$ al. ${ }^{14}$ As a positive control, we used a 355 base pair region of the $\beta$-globin gene. Primers $\beta$-globin $A$ and $\beta$-globin $B$ were obtained from published sequences. ${ }^{21}$ This positive control was necessary due to the presence of tissue PCR inhibitor(s). Fig 5a shows the results of $\beta$-globin amplification from three liver biopsy specimens taken in 1988. In all three cases a 355 base pair band could be seen, indicating successful amplification.

We next attempted to amplify the 185 base pair fragment flanked by PCR1 and PCR2 from the HBV genome from these three patients. Case 1 was serum $\mathrm{HBsAg}$ negative, while cases 2 and 3 were $\mathrm{HBsAg}$ positive. Case 1 was HBV-PCR negative while cases 2 and 3 were HBV-PCR positive (fig $5 b$ ). Thus the serological data agreed with PCR results.

Due to the ease of contamination, ${ }^{30}$ a negative control consisting of a blank tube containing PCR reagents but without liver tissues was included in each of the amplifications shown in fig 5 . In each case, no PCR product could be seen.

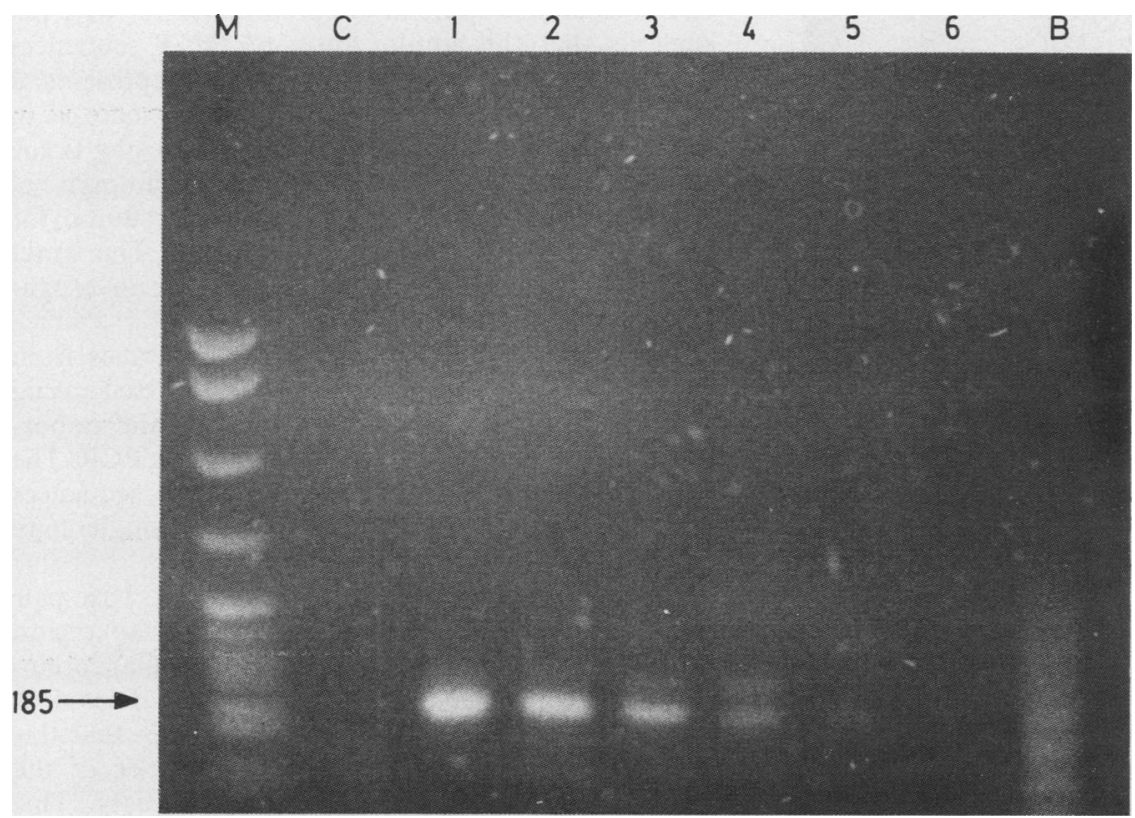

Fig 2 Amplification of the cell dilutions shown in table 2. Samples were run on a $2 \%$ agarose gel. $M=p B R 322$ digested with Msp I (marker) C, $B, 1-6$ as indicated in table 2. 


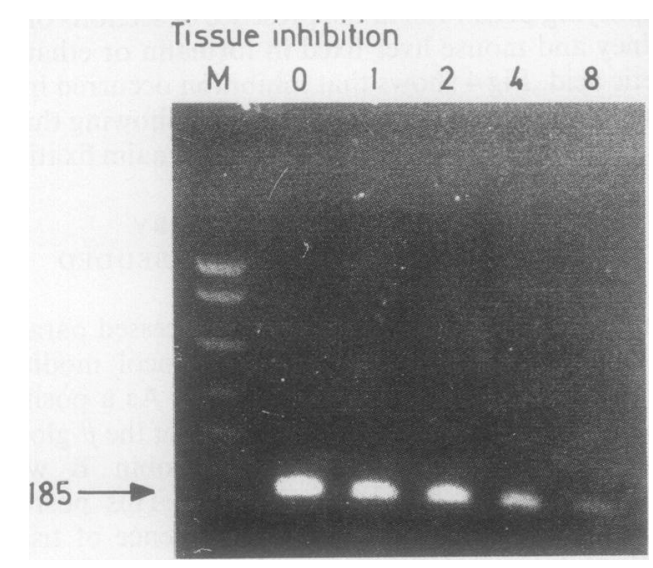

Fig 3 PCR amplification of pHBV130 (1 ng) in the presence of varying amounts of paraffin wax embedded tissue sections. Samples were run on a $2 \%$ agarose gel. $M=p B R 322$ digested with Msp I (marker): $0,1,2,4$ and 8 denote the number of tissue sections.

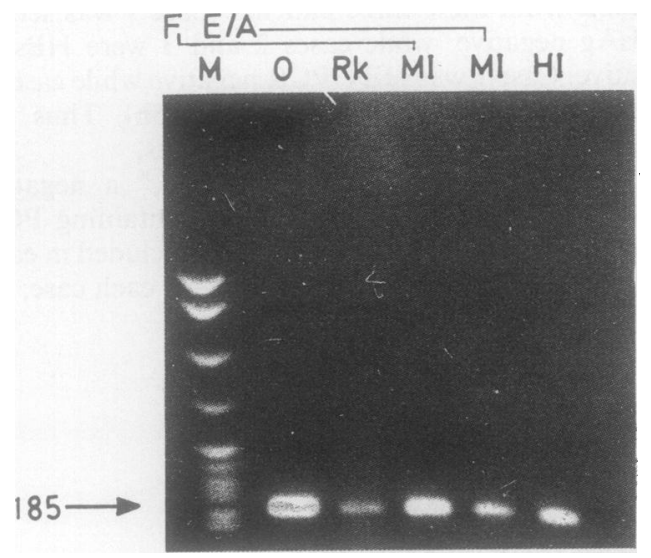

Fig 4 PCR amplification of $\mathrm{pHBVI} 30$ (1 ng) in the presence of paraffin wax embedded tissue sections from different organs and species and fixed differently. Samples were run on a $2 \%$ agarose gel. $M=p B R 322$ digested with $M s p I$ (marker); $0=$ no tissue sections; $R k=$ rat kidney; $M l(F)=$ mouse liver fixed in formalin; $M l(E / A)=$ mouse liver fixed in ethanol/acetic acid; $\mathrm{Hl}=$ human liver.

To confirm further the identity of the HBV-PCR products, we performed a Southern blot transfer of the gel shown in fig $5 \mathrm{~b}$ and probed the nitrocellulose filter with a biotinylated probe generated by PCR on pHBV130, using methods previously described. ${ }^{22}$ Primers HBVINT5 and HBVINT3 were used to amplify a 107 base pair fragment corrresponding to the centre of the 185 base pair HBV-PCR product. Results of the Southern blot hybridisation are shown in fig 5c, which shows specific hybridisation of the PCR products from cases 2 and 3 while the marker lane and the lanes corresponding to case 1 and the negative control are negative. Interestingly, there seemed to be two bands of amplification product in case 2, both of which hybridised on the Southern blot.

\section{Discussion}

In this study we successfully applied PCR to the HBV system. When used together with Southern blot hybridisation to PCR-generated biotinylated probes, the result is a sensitive, rapid, and completely nonisotopic detection system for HBV. Our sensitivity of one viral copy per 5000 cells on formalin fixed cell lines is significantly higher than conventional techniques such as the Southern blot alone, which can normally detect one viral copy per 10 cells. ${ }^{5}$ The sensitivity of the HBV-PCR, however, is likely to be less on routinely processed, paraffin wax embedded tissues due to the presence of tissue PCR inhibitors and the degradation of DNA on storage and processing. The ease with which PCR can be applied to routinely processed paraffin wax embedded tissues suggests that this technique will be very useful for large scale retrospective studies using archival material. Used in clinical situations for diagnosis of viral or other microbial infections, it has the added advantage of being noninfectious and bypasses conventional culture techniques. With the automation of PCR using programmable heating devices, this technique has the potential to be used in routine diagnosis.

The demonstration of tissue inhibitor(s) of PCR suggests that the amplification of DNA sequences from paraffin wax embedded tissues represents a delicate ballance between two factors: the increase in the amount of DNA template with increasing tissue volume; and the parallel rise in the amount of inhibition. We have tried various procedures for removing inhibition with little success. The exact nature of this inhibitor(s) requires future investigation.

The presence of PCR inhibitor(s) in tissues from various organs and species and processed using different fixation procedures underlines the importance of a positive control when performing PCR. The successful amplification of $\beta$-globin sequences provides a sensitivity index of at least a single copy level.

The inability of PCR to amplify the 185 base pair fragment from the core-polymerase overlap region from two Southern blot positive hepatocellular carcinomata suggests that this region has been deleted or mutated in these two tumours. This implies that this region is not required for the maintenance of the neoplastic state, at least in these two cases. This 


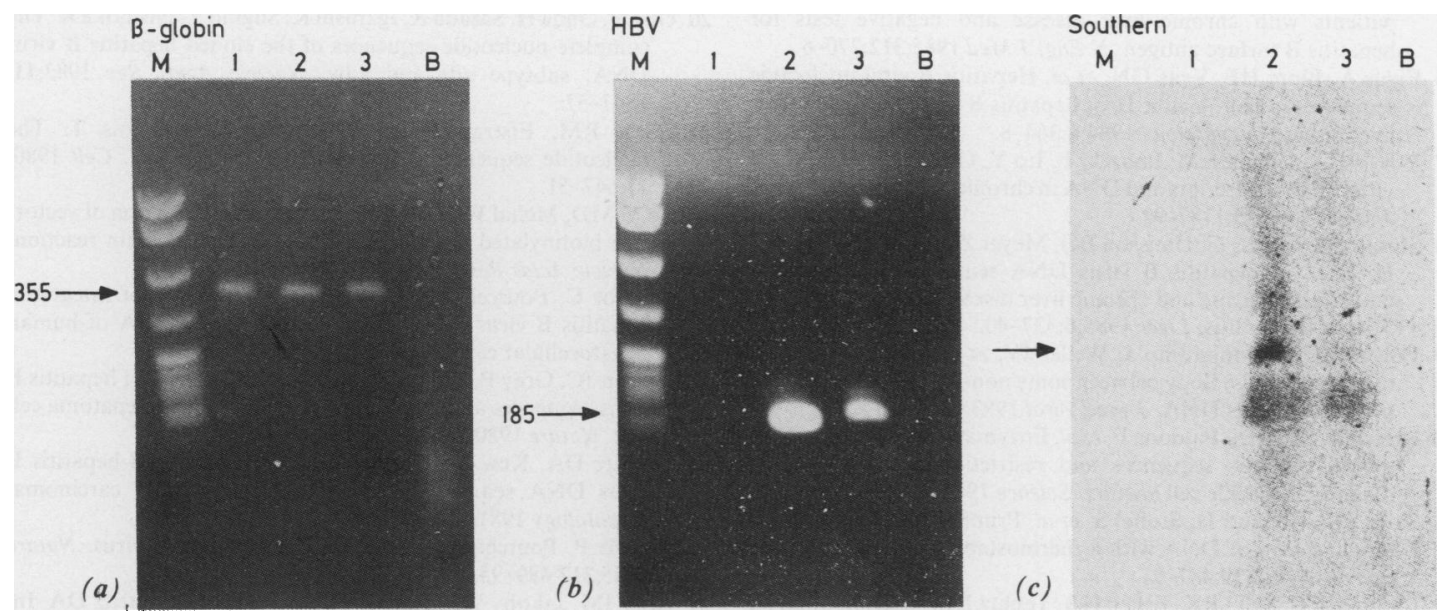

Fig 5 (a) Amplification of $\beta$-globin sequences from paraffin wax embedded liver biopsy specimens from cases 1, 2, and 3. Samples were run on a $2 \%$ Oagarose g0el. $M=p B R 322$ cut with $M$ sp I (marker), B = blank (negative control). (b) Amplification of $H B V$ sequences from paraffin wax embedded liver biopsy specimens from the same 3 cases. Case 1 was HBsAg negative while cases 2 and 3 were $\mathrm{HBsAg}$ positive. Samples were run on a $2 \%$ agarose gel.

(c) Southern blot analysis of the gel shown in (b), and hybridised with a biotinylated probe labelled by $P C R$ using primers HBVINT5 and HBVINT3 on pHBV130. Note the extra 240 base pair band in case 2 (arrow).

therefore opens up an exciting possibility that PCR, when used with different sets of primers, can be used to investigate the role of different viral genes in carcinogenesis. If such "gene-mapping" studies are carried out using conventional techniques, such as the Southern blot, at least $20 \mu \mathrm{g}$ of tumour DNA per blot (for each viral gene) is required, ${ }^{31}$ at most $1 \mu \mathrm{g}$ of DNA will be sufficient for PCR. Consequently, it is of interest to note that two recent reports have described the inability of certain PCR primers to amplify viral sequences in several cases of $\mathrm{HBV}^{32}$ and human immunodeficiency virus (HIV) infection. ${ }^{33}$ These investigators may be reporting a phenomenon similar to the one reported here.

The data from HBsAg positive liver biopsy specimens suggest that PCR is a reliable method for the detection of $\mathrm{HBV}$ in such cases. An unexpected finding has been the detection of a 240 base pair PCR product (in addition to the 185 base pair PCR product) from case 2 which hybridised with the HBV specific probe (fig $5 \mathrm{c}$ ). This may be due to sequence insertion in the HBV core-polymerase region, which could be a result of integration, or that the patient has been infected by an HBV variant. Sequencing of this fragment will help to answer these questions. When viewed together with the two cases of hepatocellular carcinomata with apparent deletion or mutation of the same region, HBV infection in man seems to be, on a genetic level, a very heterogeneous phenomenon. Thus it is conceivable that some HBsAg negative chronic liver diseases might be caused by infection with HBV variants with mutations, or deletions of the surface antigen gene, or both. The presence of genetic heterogeneity also suggests that in using PCR to diagnose viral infections, multiple primers will be necessary to maximise the chance of detecting the virus concerned.

We thank William Waggott and Sajjad Z Mehal for helpful technical assistance. Thanks are due to Dr M F Bassendine for tumour DNA, Miss J M Brown for suggesting primers $\beta$-globin $A$ and $\beta$-globin $B$, Dr $J$ Old for Pst $\beta$, and British Biotechnology Ltd for the synthesis of primers. Y-MDL is supported by the Foulkes' Foundation Fellowship and the Royal College of Pathologists. WZM is supported by the British Medical Students Trust. KAF is partially supported by the Cancer Research Campaign (UK) and the Oxford District Health Authority.

\section{References}

1 Zuckerman AJ, Sun T-T, Linsell A, Stjernsward J. Prevention of primary liver cancer. Report on a meeting of a WHO Scientific Group. Lancet 1983;i:463-5.

2 Ferrari C, Penna A, Degli Antoni A, Fiaccadori F. Cellular immune response to hepatitis B virus antigen. $J$ Hepatol 1988;7:21-33.

3 Eddleston ALWF, Mondelli M. Immunopathological mechanisms of liver cell injury in chronic hepatitis B virus infection. $J$ Hepatol 1986;3 (suppl 2):S17-S23.

4 Harrison TJ, Chen J-Y, Zuckerman AJ. Hepatitis B and primary liver cancer. Cancer Treat Rev 1986;13:1-16.

5 Brechot C, Degos F, Lugassy C, et al. Hepatitis B virus DNA in 
patients with chronic liver disease and negative tests for hepatitis B surface antigen. $N$ Engl $J$ Med 1985;312:270-6.

6 Figus A, Blum HE, Vyas GN, et al. Hepatitis B viral nucleotide sequences in non-A, non-B, or hepatitis B virus-related chronic liver disease. Hepatology 1984;4:364-8.

7 Yokosuka O, Omata M, Imazeki F, Ito Y, Okuda K. Hepatitis B virus RNA transcripts and DNA in chronic liver disease. $N$ Engl J Med 1986;315:1187-92.

8 Slusarczyk J, Hess G, Hansson BG, Meyer Zum Buschenfelde KH. Lack of hepatitis B virus DNA sequences in sera from patients with acute and chronic liver disease diagnosed as nonA, non-B hepatitis. Liver 1986;6:337-40.

9 Fowler MJF, Monjardino J, Weller IV, et al. Failure to detect nucleic acid homology between some non-A, non-B viruses and hepatitis B virus DNA. J Med Virol 1983;12:205-13.

10 Saiki RK, ScharfS, Faloona F, et al. Enzymatic amplification of $\beta$ globin genomic sequences and restriction site analysis for diagnosis of sickle cell anemia. Science 1985;230:1350-4.

11 Saiki RK, Gelfand D, Stoffel S, et al. Primer-directed enzymatic amplification of DNA with a thermostable DNA polymerase. Science 1988;239:487-91.

12 Impraim CC, Saiki RK, Erlich HA, Teplitz RL. Analysis of DNA extracted from formalin-fixed, paraffin-embedded tissue by enzymatic amplification and hybridization with sequencespecific oligonucleotides. Biochem Biophys Res Commun 1987;142:710-6.

13 Lai-Goldman M, Lai E, Grody WW. Detection of human immunodeficiency virus (HIV) infection in formalin-fixed, paraffin-embedded tissue by DNA amplification. Nucleic Acids Res 1988;16:8191.

14 Shibata DK, Arnheim N, Martin WJ. Detection of human papilloma virus in paraffin-embedded tissue using the polymerase chain reaction. $J$ Exp Med 1988;167:225-30.

15 Shibata D, Fu YS, Gupta JW, Shah KV, Arnheim N, Martin WJ. Detection of human papillomavirus in normal and dysplastic tissue by the polymerase chain reaction. Lab Invest 1988; 59:555-9.

16 Chan VT-W, Fleming KA, McGee JO'D. Detection of subpicogram quantities of specific DNA sequences on blot hybridization with biotinylated probes. Nucleic Acids Res 1985;13:8083-91.

17 Gough NM, Murray K. Expression of the hepatitis B virus surface, core and $\mathrm{e}$ antigen genes by stable rat and mouse cell lines. J Mol Biol 1982;162:43-6.

18 Alexander JJ, Bey EM, Geddes EW, et al. Establishment of a continuously growing cell line from primary carcinoma of the liver. South Africa Med J 1976;50:2124-8.

19 Howley PM. The role of papilloma virus in human cancer. In: DeVita VT Jr, Hellman S, Rosenberg SA, eds. Important advances in oncology. Philadelphia: JB Lippincott, 1987:55-73.
20 Ono Y, Onda H, Sasada R, Igarashi K, Sugino Y, Nishioka K. The complete nucleotide sequences of the cloned hepatitis $\mathrm{B}$ virus DNA; subtype adr and adw. Nucleic Acids Res 1983;11: 1747-57.

21 Lawn RM, Efstratiadis A, O'Connell C, Maniatis T. The nucleotide sequence of the human $\beta$-globin gene. Cell 1980; 21:647-51.

22 Lo Y-MD, Mehal WZ, Fleming KA. Rapid production of vectorfree biotinylated probes using the polymerase chain reaction. Nucleic Acids Res 1988:16:8719.

23 Brechot C, Pourcel C, Louise A, et al. Presence of integrated hepatitis B virus DNA sequences in cellular DNA of human hepatocellular carcinoma. Nature 1980;286:533-5.

24 Edman JC, Gray P, Valenzuela P, et al. Integration of hepatitis B virus sequences and their expression in a human hepatoma cell line. Nature 1980;286:535-8.

25 Shafritz DA, Kew MC. Identification of integrated hepatitis B virus DNA sequences in human hepatocellular carcinoma. Hepatology 1981;1:1-8.

26 Tiollais P, Pourcel C, Dejean A. The hepatitis B virus. Nature 1985;317:489-95.

27 Arias IM, Jakoby WB, Popper H, Schachter D, Shafritz DA. In The liver: biology and pathobiology. New York: Raven Press, 1988:9-10.

28 Zieman M, Garcia P, Shaul Y, Rutter WJ. Sequence of hepatitis B virus DNA incorporated into the genome of a human hepatoma cell line. J Virol 1985;53:885-92.

29 De Franchis R, Cross NCP, Foulkes NS, Cox TM. A potent inhibitor of Taq polymerase copurifies with human genomic DNA. Nucleic Acids Res 1988;16:10355.

30 Lo Y-MD, Mehal WZ, Fleming KA. False-positive results and the polymerase chain reaction. Lancet 1988,ii:679.

31 Chen J-Y, Harrison TJ, Lee C-S, Chen D-S, Zuckerman AJ. Detection of hepatitis B virus DNA in hepatocellular carcinoma: Analysis by hybridization with subgenomic DNA fragments. Hepatology 1988;8:518-23.

32 Thiers V, Nakajima E, Kremsdorf D, et al. Transmission of hepatitis B from hepatitis-B-seronegative subjects. Lancet 1988;ii:1273-6.

33 Laure F, Cougnaud V, Rouzioux C, et al. Detection of HIV1 DNA in infants and children by means of the polymerase chain reaction. Lancet 1988;ii:538-41.

Requests for reprints to: Dr K A Fleming, University of Oxford, Nuffield Department of Pathology, John Radcliffe Hospital, Oxford OX3 9DU, England. 